\title{
Grafitos de banheiro: um estudo de diferenças de gênero
}

\author{
Renata Plaza Teixeira \\ Emma Otta \\ Universidade de São Paulo
}

Resumo

Foram analisadas diferenças de gênero em grafitos de banheiro $(N=1349)$, focalizando-se aspectos da sexualidade humana. Grafitos foram coletados em banheiros de "cursinhos" prévestibulares e de uma universidade, localizados em São Paulo, SP, Brasil. Não foram encontradas diferenças de gênero significativas em termos de frequiência de grafitos sexuais. Contudo, a análise do conteúdo sexual das inscrições revelou diferenças significativas. Foi utilizado o Modelo de Regressão Logística para verificar quais categorias de grafitos sexuais diferenciavam homens de mulheres. Nos "cursinhos", as categorias diferenciadoras foram "analidade" $(B: 1,7560, g l=1, p$ $\leq 0,01)$ e "xingamento" $(B: 0,8843, g l=1, p \leq 0,01)$, temas preferidos pelos homens. Na universidade, as categorias diferenciadoras foram "xingamento" $(B: 0,4445, g l=1, p \leq$ $0,05)$ e "elogio sexual" $(B:-0,7654, g l=1, p \leq 0,05)$ : os homens produziram maior número de xingamentos, enquanto que as mulheres realizaram mais elogios. "Xingamento", portanto, foi uma categoria diferenciadora de gêneros nos dois ambientes: os homens se mostraram mais agressivos que as mulheres ao produzirem grafitos sexuais. Este resultado indica que pode haver alguma relação entre agressividade e sexualidade.

Palavras-chave: Grafitos de banheiro, Diferenças de gênero, Sexualidade, Agressividade.

\section{Abstract}

Restroom graffiti: A study of gender differences. Gender differences in restroom graffiti $(N=1349)$ were analyzed, focusing on aspects of the human sexuality. Graffiti were 
Key words: Restroom graffiti,

Gender

differences,

Sexuality, Aggressiveness. collected in restrooms from secondary schools ("cursinhos") and from a university, located in São Paulo, SP, Brazil. No significant gender differences were found in terms of frequency of sexual graffiti. However, the analysis of the sexual content of the inscriptions revealed significant differences. We used the Logistic Regression Model to verify the categories of sexual graffiti that differentiated men from women. At the secondary schools, the distinguishing categories were "anality" $(B: 1,7560, d f=1, p<.01)$ and "insult" $(B: .8843, d f=1, p<$ $.01)$, themes preferred by men. At the university, the distinguishing categories were "insult" $(B: .4445, d f=1, p<$ $.05)$ and "sexual compliment" ( $B:-.7654, d f=1, p<.05)$ : men produced a larger number of insults while women made more compliments. "Insult", therefore, was a category that differentiated genders in both locations: men were more aggressive than women when producing sexual graffiti. This result indicates that there may be some kind of connection between aggressiveness and sexuality. rafitos de banheiros, também denominados escritas latrinárias, são inscrições produzidas em banheiros públicos. Essas produções são realizadas preponderantemente nas portas, mas também ocorrem em outros lugares, tais como as paredes e o teto. Apesar de serem considerados, por alguns, meras inscrições sem sentido, produzidas ao acaso, ou simplesmente atos de vandalismo, grafitos de banheiro correspondem, na realidade, a uma importante fonte de pesquisa. A literatura brasileira referente a esse tema, no entanto, é bastante restrita.

Grafitos podem ser encontrados em diversos lugares, bem como em diferentes contextos históricos. O hábito de escrever em paredes é 
bastante antigo. Inscrições encontradas nas paredes de Pompéia atestam a antigüidade desse comportamento (Anderson \& Verplanck, 1983, p.342). Em Pompéia, os romanos produziam inscrições em grego nas paredes dos banheiros de suas casas (Neto, 1992). Esse tipo de material, portanto, pode ser analisado sob o ponto de vista da cultura.

Existem alguns poucos estudos comparando inscrições produzidas em paredes de banheiros em diferentes culturas. Olowu (1983) comparou amostras de grafitos de banheiros de universidades britânicas e nigerianas. Os dois grupos de estudantes se mostraram, em certa medida, semelhantes quanto ao modo de pensar, mas foram verificadas algumas interessantes diferenças. Superstição e animismo, por exemplo, que predominaram na amostra nigeriana, estavam ausentes na amostra britânica. Sechrest e Flores (1969) compararam inscrições produzidas em banheiros masculinos localizados, em sua maioria, em restaurantes e bares dos Estados Unidos e das Filipinas. Constataram ser igual a probabilidade de que filipinos e americanos produzissem inscrições heterossexuais. Contudo, os primeiros tinham menor probabilidade de produzir inscrições homossexuais ( $2 \%$ x $42 \%)$. Segundo os autores, a alta porcentagem de grafitos de conteúdo homossexual nos Estados Unidos pode ter sido devida ao elevado grau de conflito relacionado à homossexualidade existente nesse país.

Ahmed (1981) investigou diferenças culturais e de gênero em grafitos de quatro escolas canadenses de segundo grau, sendo duas delas francesas e duas inglesas. $\mathrm{O}$ autor observou diferença cultural relativa ao grau de envolvimento com assuntos políticos por parte dessas populações: os estudantes canadenses de origem francesa produziram maior número de inscrições de conteúdo político do que de qualquer outro tipo de conteúdo, em proporção maior que os estudantes de origem inglesa. Nwoye (1993) desenvolveu um estudo com grafitos coletados nos prédios da Universidade de Benin, na Nigéria e concluiu que, longe de serem meros atos de vandalismo, os grafitos são, na verdade, modos expressivos para articular questões sociais e políticas, adotados por grupos aos quais foram negadas outras vias de expressão pessoal. Um desses grupos corresponde à população de estudantes da maior parte do mundo. $\mathrm{O}$ autor afirma que os estu- 
dantes nigerianos, em particular, têm sido vistos como agentes de desestabilização por sucessivos governos e sofrem uma série de restrições por parte das autoridades. Por não possuírem meios para articular livremente questões sociais e políticas, os grafitos representam, para os estudantes, uma importante via de comunicação.

Em um estudo com grafitos coletados em banheiros de nove prédios do campus da Universidade de Tennessee, em Knoxville, Anderson e Verplanck (1983) concluíram que as escritas latrinárias claramente refletem importantes questões sociais contemporâneas, bem como que o conteúdo dos grafitos difere significativamente entre os prédios frequientados pelas variadas populações de estudantes. Para esses autores, observações a respeito das preocupações e interesses imediatos de populações podem ser feitas a partir daquilo que elas escrevem nas paredes dos banheiros. Segundo eles, "as paredes não apenas falam, elas gritam e, apesar de gritarem alto, é preciso ter um ouvido objetivo e ateórico para escutar a mensagem" (Anderson \& Verplanck, 1983, p.357).

Grafitos de banheiro também podem ser uma rica fonte de dados para pesquisas relativas a semelhanças e diferenças de gênero. Apesar do uso diferencial de linguagem verbal por homens e mulheres ter sido extensivamente estudado (Coyne, Sherman \& O'Brien, 1978; Levin \& Arluke, 1985; Holmes, 1992), o seu uso de linguagem escrita, particularmente grafitos, tem atraído atenção bem menor (Lowesteine, Ponticos \& Paludi, 1982). Kinsey, Pomeroy, Martin e Gebhard (1953) foram os primeiros pesquisadores a apontar a importância dos grafitos para a compreensão das diferenças de atitudes sexuais básicas. $\mathrm{Na}$ esfera reservada de um banheiro, onde o anonimato é assegurado, idéias podem surgir sem censura externa. Assim, os grafitos podem servir como um canal seguro para a expressão de impulsos sexuais. No entanto, essa autonomia conferida pela situação de anonimato poderia ser relativa: se, por um lado, não há censura externa, por outro, existem regras internalizadas que levam as pessoas a se submeter a uma censura interior. De qualquer modo, grafitos de banheiro podem revelar fantasias trazidas para o registro da escrita em um local que permite a leitura dessas inscrições por parte de um grande número de pessoas. 
Ahmed (1981), que estudou grafitos produzidos por estudantes canadenses de segundo grau, constatou que as meninas escreveram muito mais que os meninos, dado que difere dos resultados alcançados por estudos anteriores. Nos banheiros femininos, mais do que nos masculinos, predominaram inscrições românticas, ao invés de eróticas. Não foram verificadas diferenças de gênero quanto à proporção entre a quantidade de grafitos relacionados a sexo e o número total de grafitos.

Ao estudarem a influência que o nível socioeconômico exerce na produção das escritas latrinárias, Wales e Brewer (1976) verificaram que inscrições predominantemente românticas foram produzidas por estudantes de segundo grau do sexo feminino de nível socioeconômico mais baixo. Com o aumento do nível socioeconômico, as escritas latrinárias realizadas pelas mulheres se tornaram menos românticas e mais eróticas, sendo que no nível socioeconômico mais elevado ambas as categorias ficaram aproximadamente equivalentes. Sechrest e Olson (1971) estudaram inscrições de paredes de banheiros masculinos em quatro tipos de instituições de ensino médio e superior nos Estados Unidos que também diferiam quanto aos níveis socioeconômicos. As instituições que atraíam maior número de estudantes provenientes de estratos socioeconômicos mais altos eram as escolas profissionais (cursos universitários que formam, por exemplo, médicos, advogados, dentistas) e os cursos universitários com duração de quatro anos. Por outro lado, a maior parte dos estudantes das faculdades juniores (faculdades nos Estados Unidos e no Canadá em que os alunos estudam por dois anos) e das escolas de comércio provinha de estratos socioeconômicos mais baixos. Os autores observaram que inscrições heterossexuais se mostraram mais freqüentes em escolas de comércio e escolas profissionais. Também constataram que expressões de hostilidade, direcionadas em especial contra grupos raciais e étnicos, foram mais frequientes e variadas nas escolas de comércio e nas faculdades juniores do que em outras instituições, ou seja, estiveram mais fortemente presentes na população de estudantes de nível socioeconômico mais baixo.

As escritas latrinárias também já foram material de estudo para se analisar a personalidade adolescente. Peretti, Carte e McClinton (1977) 
desenvolveram uma pesquisa com grafitos escritos por jovens. Foram coletados grafitos dos banheiros freqüentados por alunos da sétima e oitava séries de quatro escolas de primeiro grau de Chicago. As inscrições foram consideradas representativas da personalidade do adolescente. Verificaram-se diferenças significativas entre meninos e meninas. No início da personalidade adolescente, os grafitos mais freqüentes lidaram com a sexualidade. Observando-se as categorias de "maturidade sexual", "atividade sexual" foi mais freqüente para os meninos, enquanto que "desejo sexual" foi mais freqüente para as meninas. Portanto, o início da personalidade adolescente masculina parece tender mais para a atividade sexual, enquanto que a personalidade adolescente feminina parece inclinar-se para o desejo sexual.

O final dos anos 60 e início dos anos 70 foram caracterizados por grandes mudanças sociais. Parece haver ampla evidência de que atitudes relativas a papéis sexuais mudaram (Mason, Czajka \& Arber, 1976; Thorton \& Freedmam, 1979). Mulheres tentaram liberar-se dos papéis convencionais de gênero. Duplos padrões morais foram questionados. Mulheres se tornaram sexualmente mais agressivas (Arluke, Kutakoff \& Levin, 1987). Surpreendentemente, grafitos de banheiro têm revelado atitudes tradicionais de papéis sexuais. Apesar de a privacidade e o anonimato estarem garantidos nos banheiros, vários pesquisadores descobriram que autores de grafitos freqüentemente seguiram estratégias de comunicação socialmente condicionadas.

Kutakoff (1972) examinou mais de 500 grafitos de banheiros de faculdades situadas na região de Boston. As mulheres produziram um número muito menor de grafitos do que os homens. Também produziram menor número de obscenidades e de referências a masturbação, homossexualidade, relação sexual ou doença venérea. Os grafitos femininos, portanto, mostraram-se mais conservadores, convencionais e subordinados a padrões de decência da classe média.

É interessante verificar que a diferença de gênero parece ter aumentado ao longo do tempo no que se refere às inscrições produzidas em banheiros, ao invés de ter diminuído. Arluke, Kutakoff e Levin (1987) descobriram que as estudantes universitárias na área de BostonCambridge produziram grafitos com um menor número de referências 
sexuais que os estudantes do sexo masculino. Durante os anos 70, $25 \%$ dos grafitos femininos, contrastando com $35 \%$ dos grafitos masculinos, referiam-se a temas sexuais. Por sua vez, na década de 80 , foi encontrada uma quantidade significativamente maior de grafitos sexuais nos banheiros masculinos (46\%) do que nos femininos (26\%). Assim sendo, na realidade a diferença entre os sexos aumentou, já que as produções femininas não sofreram mudanças significativas, enquanto que as masculinas apresentaram um número significativamente maior de grafitos com conteúdo sexual.

Otta (1993) estudou inscrições em paredes de banheiro em prédios de uma universidade brasileira. Assim como Kutakoff (1972), observou que os homens produziram mais inscrições que as mulheres, mas, por outro lado, conteúdos sexuais estavam igualmente representados nos banheiros masculinos e femininos. Comentários relativos à AIDS foram citados pela autora, mas não o foram em estudos prévios. Apesar dos conteúdos sexuais serem igualmente representados nos banheiros masculinos e femininos, romantismo, problemas pessoais e moralidade prevaleciam nos banheiros femininos.

Estudando grafitos produzidos por estudantes universitárias americanas, Cole (1991) verificou que as inscrições femininas eram principalmente interpessoais, interativas, envolvendo conselhos e direcionadas a relacionamentos. Bruner \& Kelso (1980), por outro lado, constataram que os grafitos masculinos se mostraram mais pejorativos, negativos e hostis, objetivando subordinar indivíduos considerados inferiores segundo a raça, a orientação sexual ou o gênero. Apesar das interessantes análises qualitativas, estes estudos podem ser criticados por serem basicamente impressionistas e anedóticos.

Otta et al. (1996) fizeram um estudo comparativo de grafitos produzidos em "cursinhos" e em uma universidade da cidade de São Paulo (SP), Brasil. Uma primeira análise quantitativa dos dados dessa pesquisa, ao contrário do que se esperava, não revelou diferenças em termos de gênero na categoria sexo considerada amplamente, tanto relativamente aos grafitos produzidos nos cursinhos quanto àqueles encontrados no campus da universidade. No entanto, uma análise mais pormenorizada do conteúdo dessa categoria poderia revelar even- 
tuais diferenças quanto à produção masculina e feminina. O presente estudo foi realizado com o objetivo de efetuar essa análise.

Diferenças e semelhanças de gênero podem ser estudadas através dos grafitos. Contudo, não existem muitas pesquisas abordando esse tema e a escassez é ainda maior no Brasil. Sendo os grafitos um canal pelo qual os indivíduos veiculam idéias, expressam fantasias e manifestam facetas de seu comportamento, é importante que esse material seja analisado.

Sob a hipótese de que homens e mulheres diferem quanto à produção de grafitos verbais sexuais, procedemos à análise do conteúdo desses escritos. Por serem verbais, essas produções são um pouco menos sujeitas à interpretação do que as não-verbais (Peretti, Carte \& McClinton, 1977), tais como os desenhos. Além disso, grafitos escritos podem esclarecer aspectos das personalidades social e privada dos indivíduos (Mendel,1974; Singer, 1974).

Qualquer tipo de escritura, de fato, tem muito a revelar não só a respeito de seu autor, mas também da época e do local em que foi produzida. As escritas latrinárias, pelas condições especiais de produção, seguramente constituem importante fonte de conhecimento acerca dos fenômenos psicológicos humanos, bem como de aspectos sociais e culturais da humanidade.

Com o presente estudo, buscou-se examinar a validade da hipótese de que homens e mulheres diferem quanto à produção de grafitos sexuais, verificando-se quais conteúdos desse tipo de grafitos são promotores de diferenciação de gênero.

\section{Método}

Vinte e oito banheiros masculinos e vinte e oito banheiros femininos foram pesquisados na área metropolitana de São Paulo (SP), Brasil. Metade dos banheiros pertencia a cursinhos (os dados foram coletados em três cursinhos) e a outra metade em um campus universitário (os dados foram coletados em seis prédios do campus principal, especificamente Economia e Administração, Ciências Sociais, Matemática, Biociências, Educação e Arquitetura). Em cada prédio, foram examinados banheiros localizados acima do andar térreo como 
forma de minimizar o uso por parte de visitantes. Os banheiros de empregados foram excluídos. Foram sempre amostrados um banheiro masculino e um feminino próximos um do outro. Dados foram coletados durante um período de três meses (setembro a novembro), em 1992. Uma vez que os banheiros não são pintados com frequiência, foi possível coletar um grande número de inscrições. Esquemas de lavagens diárias não incluíram as paredes.

Cada grafito foi copiado, para evitar interpretação, preconceitos, e classificado como inscrição verbal ou desenho. Inscrições verbais foram subseqüientemente classificadas em uma de dezoito categorias, que incluíram os seguintes temas: presença, esportes, religião, preconceito, insulto, política, romantismo, sexo, drogas, música, crítica ao grafito, escatológico, humor, filosofia, gramática, escola, higiene e outros. Os desenhos foram classificados em uma de quatro categorias: romantismo, sexo, símbolos e outros. As categorias eram mutuamente excludentes, para que todos os grafitos fossem classificados em apenas uma categoria.

Seguem, abaixo, alguns exemplos de grafitos e sua classificação: esteve aqui (presença);

- Inconsciente coletivo é pegar ônibus errado (humor);

- Urnas não são penico, vote em ........... (seguido pelo nome de um candidato a governador de São Paulo nas eleições de 1990) (política);

- Saber viver é acreditar que a semana seguinte será melhor do que $a$ anterior (filosofia);

- Se você quer aprender sobre os prazeres do sexo ligue-me e não se arrependerá (seguido por um número de telefone) (sexo).

Foram usados os mesmos critérios de Sechrest \& Flores (1969) e Wales \& Brewer (1976) para determinar a unidade de resposta. Uma unidade era qualquer produção realizada pelo que as evidências indicavam ser um indivíduo em uma determinada ocasião. As principais pistas usadas para a identificação de uma unidade de resposta foram tipos de escrita, tipos de ferramentas de escrita, cor, proximidade e consistência temática. Uma única palavra foi considerada uma unida- 
de, bem como uma lista de membros de uma gangue. Inscrições que eram respostas ou comentários a respeito de outras inscrições foram consideradas como distintas unidades de resposta. Três avaliadores classificaram cada grafito de acordo com categorias de conteúdo. Para aferir o grau de fidedignidade, $20 \%$ dos dados, escolhidos ao acaso, foram julgados pelos avaliadores. $\mathrm{O}$ grau de fidedignidade foi calculado dividindo-se o número de classificações em que os julgadores concordaram pelo total de inscrições classificadas. $\mathrm{O}$ grau de fidedignidade entre os juízes foi de 0,93 para inscrições verbais e 0,95 para desenhos.

Com o objetivo de investigar a sexualidade expressa através dos grafitos verbais, foi realizada uma segunda categorização desse material. Todo e qualquer grafito verbal cujo conteúdo fizesse referência a sexo foi analisado. Assim, grafitos que haviam sido anteriormente classificados, por exemplo, nas categorias "esporte" ( $E$ o destino corintiano comer o cú de São Paulino) ou "insulto" (FAU só dá bicha e prostituta), devido a serem estes seus conteúdos predominantes, foram subseqüentemente categorizados como sexuais, contanto que se reportassem, de alguma forma, a sexualidade. Foram levantadas treze categorias de sexualidade: pênis, vagina, defecação, analidade, xingamento, elogio sexual, erotismo, relação sexual, seios, impotência, masturbação, AIDS e outros. Desde que houvesse algum termo abordando um desses temas, o grafito era classificado na respectiva categoria. Algumas vezes, um mesmo grafito foi classificado em mais de uma categoria (por exemplo, a inscrição Neste cursinho só tem uma mina gostosa. Mais é galinha foi categorizada em "elogio sexual" e "xingamento").

\section{Resultados}

Dos 286 grafitos verbais ligados a sexualidade analisados no presente estudo, $38 \%$ vieram dos cursinhos e $62 \%$ da universidade. A maior parte dos grafitos verbais de conteúdo sexual foi produzida por estudantes universitários, apesar destes, de maneira global, grafitarem menos que os estudantes de "cursinho": do total geral de 1349 grafitos coletados, $63 \%$ provinham dos cursinhos e $37 \%$ eram procedentes da universidade. 
A nova categorização dos grafitos sexuais elevou a porcentagem de inscrições com conteúdo sexual em relação ao estudo inicial tanto nos cursinhos (de $7 \%$ para $14 \%$ ) quanto na universidade (de $31 \%$ para $39 \%$ ). A grande elevação da frequiência de inscrições classificadas como sexuais nos cursinhos deveu-se principalmente ao fato de haver uma quantidade alta de grafitos de insulto que passaram a ser considerados de conteúdo sexual por conterem xingamentos que, de alguma forma, achavam-se ligados à temática da sexualidade.

A Tabela 1 apresenta as quantidades e porcentagens de temas ligados a sexualidade empregados por homens e mulheres nos grafitos verbais produzidos nos cursinhos e na universidade.

Foi utilizada a técnica de Regressão Logística, com o objetivo de verificar que categorias de grafitos sexuais diferenciavam significativamente homens de mulheres. Duas equações de regressão logística foram estimadas, uma para cada ambiente - "cursinho" e universidade. Utilizou-se o programa SPSS (Statistical Package for the Social Sciences).

Tabela 1 - Freqüências absolutas e relativas de temas ligados a sexualidade empregados por homens e mulheres estudantes de "cursinho" e universitários

\begin{tabular}{|c|c|c|c|c|c|c|c|c|}
\hline \multirow[t]{3}{*}{ Temas } & \multicolumn{4}{|c|}{ "Cursinho" } & \multicolumn{4}{|c|}{ Universidade } \\
\hline & \multicolumn{2}{|c|}{ Homens } & \multicolumn{2}{|c|}{ Mulheres } & \multicolumn{2}{|c|}{ Homens } & \multicolumn{2}{|c|}{ Mulheres } \\
\hline & $n$ & $\%$ & $n$ & $\%$ & $n$ & $\%$ & $n$ & $\%$ \\
\hline Pênis & 12 & 8,76 & 9 & 14,75 & 19 & 12,42 & 12 & 10,62 \\
\hline Vagina & 9 & 6,57 & 0 & 0 & 14 & 9,15 & 15 & 13,27 \\
\hline Defecação & 9 & 6,57 & 1 & 1,64 & 6 & 3,92 & 0 & 0 \\
\hline Analidade & 30 & 21,90 & 2 & 3,28 & 20 & 13,07 & 10 & 8,85 \\
\hline Xingamento & 38 & 27,74 & 15 & 24,59 & 27 & 17,65 & 10 & 8,85 \\
\hline Elogio sexual & 5 & 3,65 & 11 & 18,03 & 3 & 1,96 & 11 & 9,73 \\
\hline Erotismo & 0 & 0 & 2 & 3,28 & 0 & 0 & 3 & 2,65 \\
\hline Relação sexual & 28 & 20,44 & 19 & 31,14 & 44 & 28,76 & 31 & 27,43 \\
\hline Seios & 0 & 0 & 0 & 0 & 1 & 0,65 & 3 & 2,65 \\
\hline Impotência & 2 & 1,46 & 0 & 0 & 1 & 0,65 & 0 & 0 \\
\hline Masturbação & 0 & 0 & 0 & 0 & 4 & 2,61 & 2 & 1,77 \\
\hline AIDS & 1 & 0,73 & 0 & 0 & 3 & 1,96 & 0 & 0 \\
\hline Outros & 3 & 2,19 & 2 & 3,28 & 11 & 7,19 & 16 & 14,16 \\
\hline Total & & 37 & & 1 & & 53 & & \\
\hline
\end{tabular}


A análise dos dados revelou que homens e mulheres diferem quanto à produção de grafitos ligados à sexualidade no que se refere ao conteúdo dessas inscrições. Nos cursinhos, as categorias que diferenciaram os homens das mulheres foram "analidade" $(B: 1,7560, g l=$ $1, p \leq 0,01)$ e "xingamento" ( $B: 0,8843, g l=1, p \leq 0,01)$, conforme se pode observar na Tabela 2 . Ambos os temas foram mais abordados pelos homens que pelas mulheres, sugerindo maior analidade e agressividade dos estudantes de "cursinho" do sexo masculino.

A Tabela 3 apresenta os temas que diferenciaram homens de mulheres na universidade. O tema "xingamento" também diferenciou

Tabela 2 - Resultado de regressão logística para os temas ligados a sexualidade que diferenciam significativamente homens de mulheres nos "cursinhos"

\begin{tabular}{|c|c|c|}
\hline Temas & \multicolumn{2}{|c|}{ "Cursinho" } \\
\hline & Coeficiente & 0,4124 \\
\hline Analidade & $1,7560 * *$ & 0,2648 \\
\hline Xingamento & $0,8843 * *$ & 0. \\
\hline
\end{tabular}

Os coeficientes podem ser interpretados de forma tal que uma mudança de uma unidade na variável independente resulta em uma mudança de uma unidade no log likelihood de um resultado favorável. A razão log likelihood para a equação é $(-2 \ln l)=95,348$.

$* * \mathrm{p} \leq 0,01$.

homens de mulheres $(B: 0,4445, g l=1, p \leq 0,05)$ no ambiente universitário, sendo que os homens apresentaram maior número de grafitos classificados nessa categoria. Outro tema que diferenciou homens de mulheres no campus universitário foi a categoria "elogio sexual" ( $B$ : $0,7654, g l=1, p \leq 0,05)$. Com relação aos elogios, as mulheres apresentaram frequiência bastante maior de grafitos contendo termos classificáveis nessa categoria (gostosa, tesão etc.) que os homens. Assim, categorias opostas ("xingamento" x "elogio sexual") diferenciaram homens e mulheres universitários, indicando maior nível de agressividade também entre os estudantes do sexo masculino pertencentes à amostra universitária.

A categoria "xingamento", que diferenciou homens de mulheres tanto no "cursinho" quanto na universidade, foi submetida a uma análise de conteúdo, com o objetivo de se verificar contra quem a agressividade expressa por intermédio dos grafitos sexuais se dirigia. 
Tabela 3 - Resultados de regressão logística para os temas ligados a sexualidade que diferenciam significativamente homens de mulheres na universidade

\begin{tabular}{|l|c|c|}
\hline Temas & \multicolumn{2}{|c|}{ Universidade } \\
\hline & Coeficiente & EP \\
\hline Xingamento & $0,4445 *$ & 0,3379 \\
\hline Elogio sexual & $-0,7654 *$ & 0,2059 \\
\hline
\end{tabular}

${ }^{\mathrm{b}}$ A razão $\log$ likelihood para a equação é $(-2 \ln \mathrm{l})=231,004$.

$* \mathrm{p} \leq 0,05$.

Foram levantadas cinco categorias de xingamento, conforme os termos empregados nos grafitos: "Homossexual Masculino" (por exemplo, bicha e viado), "Homossexual Feminino" (sapatão e entendida), "Prostituta" (puta e vagabunda), "Homem Traído" (corno) e "Outros" (brocha e bundão).

Utilizou-se o teste do qui-quadrado para se verificar quais categorias de xingamento apresentavam diferenças de gênero significativas. Alguns dados interessantes foram observados, conforme se pode verificar na Tabela 4.

Nos cursinhos, homens xingaram principalmente homossexuais masculinos e o fizeram com freqüência significativamente maior que

Tabela 4 - Freqüências absolutas e relativas de termos utilizados em xingamentos empregados por estudantes de "cursinho" e universitários, bem como respectivos valores de qui-quadrados

\begin{tabular}{l|c|c|c|c|c|c|c|c|c|c|}
\hline $\begin{array}{c}\text { Categorias de } \\
\text { xingamento }\end{array}$ & \multicolumn{5}{|c|}{ "Cursinho" } & \multicolumn{5}{c|}{ Universidade } \\
\hline & Homens & Mulheres & $\chi^{2}$ & Homens & Mulheres & $\chi^{2}$ \\
\hline & $n$ & $\%$ & $n$ & $\%$ & & $n$ & $\%$ & $n$ & $\%$ & \\
\hline Hom.Masculino & 23 & 67,6 & 1 & 4,2 & $20,8^{* *}$ & 33 & 75,0 & 3 & 13,0 & $20,9 * *$ \\
\hline Hom.Feminino & 0 & 0 & 1 & 4,2 & 0,0 & 0 & 0 & 12 & 52,2 & $24,5 * *$ \\
\hline Prostituta & 7 & 20,6 & 19 & 79,2 & $17,2 * *$ & 3 & 6,8 & 7 & 30,4 & $4,9 *$ \\
\hline Homem traído & 1 & 2,9 & 0 & 0 & 0,7 & 4 & 9,1 & 0 & 0 & 0,9 \\
\hline Outros & 3 & 8,8 & 3 & 12,5 & 0 & 4 & 9,1 & 1 & 4,3 & 0,2 \\
\hline Total & 34 & & 24 & & & 44 & & 23 & & \\
\hline
\end{tabular}

Hom.Masculino = Homossexual Masculino e Hom.Feminino = Homossexual Feminino. ${ }^{*} p \leq 0,05$. ** $p \leq 0,001$. 
as mulheres $\left(67,65 \% \times 4,17 \% ; \chi^{2}(N=58)=20,83, g l=1, p \leq 0,001\right)$. Não houve diferença significativa entre homens e mulheres no tocante a xingamentos dirigidos contra homossexuais femininos nos cursinhos. No entanto, nesse ambiente, estudantes do sexo feminino produziram xingamentos dirigidos contra prostitutas com freqüência significativamente maior que os do sexo masculino $\left(79,17 \% \times 20,59 \% ; \chi^{2}(N=\right.$ 58) $=17,22, g l=1, p \leq 0,001)$.

Na universidade, a freqüência de xingamentos contra homossexuais masculinos também foi significativamente maior entre os homens que entre as mulheres $\left(75,00 \%\right.$ x $13,04 \% ; \chi^{2}(N=67)=20,90, g l$ $=1, p \leq 0,001)$. As mulheres, por outro lado, passaram a dirigir sua agressividade, de maneira mais incisiva que os homens, contra homossexuais femininos $\left(52,17 \% \times 0 \% ; \chi^{2}(N=67)=20,90, p \leq 0,001\right)$. Continuaram a xingar prostitutas com frequiência maior que os homens, mas não tão enfaticamente quanto nos cursinhos $(30,43 \% \mathrm{x}$ $\left.6,82 \% ; \chi^{2}(N=67)=4,90, g l=1, p \leq 0,05\right)$. Elas, com efeito, diferiram mais dos homens ao xingarem lésbicas que ao xingarem prostitutas.

Os homens apresentaram certa constância de comportamento no tocante aos xingamentos produzidos em grafitos de conteúdo sexual: revelaram-se especialmente agressivos contra homossexuais masculinos tanto nos cursinhos quanto na universidade e foi esse tipo de xingamento que os diferenciou significativamente das mulheres. Estas, por outro lado, apresentaram comportamentos agressivos diversos nos dois ambientes pesquisados. Apesar de, tanto nos cursinhos quanto na universidade, diferenciarem-se dos homens no tocante a xingamentos contra prostitutas, essa diferença foi um pouco menor no ambiente universitário. Na universidade, as mulheres diferiram significativamente dos homens quanto a xingamento contra homossexuais femininos. Assim, enquanto os homens mantiveram seu alvo de agressividade nos dois ambientes, as mulheres apresentaram mudança no foco de agressão.

A análise por Regressão Logística é muito interessante por revelar categorias diferenciadoras de gênero, através da comparação entre o efeito de cada categoria e o efeito médio de todas as categorias (Norusis, 1993). Contudo, a observação da Tabela 1 nos mostra que homens e mulheres escreveram muito sobre "relação sexual". Apesar 
do alto índice de grafitos nessa categoria não ter promovido diferenciação de gênero, esse resultado da pesquisa revela um grande interesse por sexo tanto por homens quanto por mulheres nos dois ambientes estudados. É interessante verificar que os homens produziram número maior de grafitos relacionados a atividade sexual nos cursinhos. As mulheres, por outro lado, mostraram-se mais interessadas por esse tema na universidade.

\section{Discussão}

Uma primeira análise geral dos grafitos que foram objeto desta pesquisa (Otta et al., 1996) não havia revelado diferenças de gênero quanto à categoria sexo considerada amplamente. Uma nova análise do material, examinando-se os diversos temas abrangidos pela categoria sexo, contudo, apontou diferenças significativas.

A análise dos grafitos sexuais pela técnica da Regressão Logística indicou quais categorias de conteúdo sexual diferenciaram significativamente homens de mulheres, tanto nos cursinhos quanto na universidade. Nos dois ambientes pesquisados, "xingamento" se destacou como a categoria que diferenciou homens de mulheres: os homens xingaram mais, principalmente nos cursinhos. Sendo esta a principal categoria que distinguiu os gêneros, a agressividade se tornou um fator relevante neste estudo.

Existe uma série de teorias que tentam explicar a agressividade humana, relacionando-a inclusive à sexualidade. Eibl-Eibesfeld (1989) relata a hipótese de que a agressão e o medo se achem relacionados à excitação sexual. No homem, haveria uma relação positiva entre agressão e excitação sexual. Já no sexo feminino, a agressão parece inibir a sexualidade. A grande quantidade de grafitos sexuais agressivos produzidos pelos homens pode ser interpretada em termos de associação entre excitação sexual e agressão. Assim, talvez os homens tenham produzido xingamentos movidos não só pelo impulso de agredir, mas também pela excitabilidade que pode estar envolvida nesse comportamento. Por outro lado, o fato das mulheres terem produzido uma quantidade bem menor de xingamentos que os homens revela que a sexualidade feminina realmente não parece ser estimulada por comporta- 
mentos agressivos. No entanto, apesar de em grau menor, a agressividade feminina se mostrou presente nos grafitos. Outras motivações, contudo, poderiam levar as mulheres a produzir esse tipo de inscrições.

A agressão masculina, tanto nos cursinhos quanto na universidade, voltou-se principalmente contra homossexuais do sexo masculino. Os homens produziram um número significativamente maior de termos agressivos contra homossexuais masculinos que as mulheres. Segundo Innala e Ernulf (1992), o banheiro masculino pode ser sexualmente atraente para os homossexuais sadomasoquistas, especialmente para os submissos, já que é possível que exista um componente masoquista, de auto-humilhação em expressar desejos sexuais dentro de um banheiro. A agressividade, presente tanto no comportamento sadomasoquista quanto no ato de grafitar mensagens contendo xingamentos, pode estar ligada aos mecanismos disparadores de excitação sexual envolvidos na relação entre excitação e agressão citada por Eibl-Eibesfeld (1989).

A atitude negativa para com homossexuais masculinos e lésbicas foi estudada por Kerns e Fine (1994). Esses autores constataram que, da amostra pesquisada composta por 155 estudantes de uma universidade católica privada do meio-oeste dos Estados Unidos da América, os homens apresentam maior número de atitudes negativas com relação a homossexuais masculinos que as mulheres. Não foram verificadas diferenças de gênero relativamente às atitudes para com as lésbicas. O presente estudo, contudo, revelou diferença significativa quanto à produção de xingamentos voltados contra as lésbicas no ambiente universitário: as mulheres xingaram homossexuais do sexo feminino com freqüência significativamente maior que os homens. Essa diferença, no entanto, não foi observada nos cursinhos.

Herek (1989) sugeriu que a violência contra homossexuais de certo modo reforça os papéis de gênero tradicionais e deprecia atributos femininos em outros homens. Assim, ao grafitarem xingamentos contra homossexuais masculinos, os homens podem estar buscando reafirmar os papéis tradicionais que exercem dentro da sociedade. Ao mesmo tempo, podem estar hostilizando aspectos femininos dos homossexuais que atacam, revelando uma atitude duplamente preconceituosa: contra gays e contra mulheres. 
Tanto nos cursinhos quanto na universidade, as mulheres xingaram prostitutas com freqüência significativamente maior que os homens, sendo essa diferença mais marcada nos cursinhos. Burbank $(1987,1994)$ observou que as mulheres são mais freqüentemente agressivas contra outras mulheres do que contra homens.

Ao estudarem desejos pessoais de homens e mulheres, Ehrlichman e Eichenstein (1992) constataram que estudantes do sexo feminino de duas universidades norte-americanas, localizadas em região metropolitana e em área suburbana, preferiram sexo com compromisso a sexo casual. Segundo Michael, Gagnon, Laumann e Kolata (1975), é muito mais provável que os homens tenham um número bem maior de parceiros sexuais que as mulheres. Silva (1996) relata que existem evidências de que as mulheres rejeitem o sexo casual com intensidade bem maior que os homens (Clark e Hattfield, 1989) e cita a teoria do investimento parental para explicar essa diferença. As mulheres têm mais a investir na gravidez e criação dos filhos que os homens. Assim, em termos evolutivos, aquelas mulheres que só aceitavam sexo com homens que dessem indícios de que gostassem delas aumentavam as chances de deixar descendentes, pois poderiam partilhar com um companheiro os encargos decorrentes da gravidez. Os homens que freqüentemente praticavam sexo casual, por outro lado, tinham muito a ganhar, pois com esse comportamento eles aumentavam a probabilidade de passar seu material genético para as gerações seguintes. Ao grafitarem mensagens contendo xingamentos que fazem referências a prostitutas, as mulheres, além de revelar uma atitude preconceituosa, podem estar se voltando contra um comportamento sexual que é do tipo eventual, sem compromisso. É como se menosprezassem a mulher prostituta por não garantir a presença de um companheiro com quem pudessem compartilhar o cuidado da prole.

O psicanalista Lomas (1980) considera o próprio ato de grafitar como sendo um ato agressivo. O autor afirma que os dados clínicos sustentam a hipótese de que o ato de escrever na parede acha-se conectado a sentimentos de ser excluído, negligenciado ou separado. Escrever nas paredes corresponde a uma ação destrutiva provocada por esses sentimentos. "Entre outras coisas, os grafitos são o produto de um ato de vingança" (Lomas, 1980, p.142). O autor enfatiza o 
sentimento de exclusão como sendo o incidente provocador desse ato. Destaca, ainda, que escrever nas paredes compreende um esforço de dominar ativamente uma humilhação experienciada passivamente. Assim, a agressividade contida nos grafitos de xingamento poderia estar, na verdade, apenas exarcebando o caráter já agressivo do próprio ato de grafitar.

White (1977) afirma que o anonimato aumenta a probabilidade de haver comportamento contra as normas, agressivo e/ou destrutivo. $\mathrm{O}$ espaço reservado do banheiro oferece a condição de anonimato que, se por um lado fornece aos grafiteiros relativa privacidade na qual possam expressar seus pontos de vista sem medo (Nwoye, 1993), por outro também fomenta o comportamento agressivo.

Além da categoria "xingamento", homens diferiram de mulheres estudantes de "cursinho" quanto à categoria "analidade". Na universidade, no entanto, o tema da analidade, apesar de presente, mostrouse menos importante, não mais se revelando diferenciador de gênero. Esta mudança de grau de interesse pelo tema da analidade com o aumento do nível de escolaridade e de idade pode ser decorrente do desenvolvimento sexual dos indivíduos. De qualquer forma, esse tema esteve presente e pode estar relacionado a fantasias sexuais masculinas. Segundo Innala e Ernulf (1992), a análise dos grafitos sexuais pode revelar quais comportamentos sexuais são preferidos pelos homens, tanto no plano da fantasia quanto no do próprio comportamento.

Na universidade, os gêneros se diferenciaram por duas categorias sexuais opostas: "xingamento" e "elogio sexual". Os homens xingaram mais, enquanto que as mulheres produziram maior número de elogios sexuais. Segundo Bruner e Kelso (1980), os indivíduos que produzem grafitos freqüentemente seguem estratégias de comunicação socialmente condicionadas e orientadas de acordo com o gênero. Os grafitos masculinos são, em geral, mais negativos, agressivos e hostis que os produzidos por mulheres. Os grafitos femininos, por outro lado, costumam ser interpessoais, interativos. Os dados da presente pesquisa confirmam esses padrões de comportamento: os homens foram mais agressivos e as mulheres mais interativas, já que, ao 
produzirem grafitos elogiosos, elas de certa forma buscaram uma interação com as suas interlocutoras.

Existe uma série de estudos que abordam a questão da agressividade feminina (Burbank, 1987,1994; Björkqvist, 1994), muitas vezes constatando que não há razões para se acreditar que as mulheres sejam menos hostis que os homens (Björkqvist, 1994). Por outro lado, o estereótipo de que as mulheres são mais emocionais que os homens encontra-se relatado na literatura. Sprecher e Sedikides (1993) desenvolveram um estudo com casais heterossexuais com o objetivo de verificar diferenças de gênero nas percepções da emoção. As mulheres, em geral, acreditavam ser mais emocionais do que os homens e relataram haver experienciado tanto emoções positivas quanto negativas em seus relacionamentos em um grau mais elevado que seus parceiros. Essa característica de se sentir experienciando maior nível de emoções positivas parece estar relacionada com a grande produção de elogios nas mensagens sexuais femininas. As mulheres, ao menos, revelaram maior liberdade para produzir grafitos elogiosos em suas formações discursivas de caráter sexual.

Grafitos de banheiro são uma rica fonte para estudos relativos à sexualidade. Correspondem a mais um canal através do qual os indivíduos podem se expressar e acabam por revelar interessantes aspectos de suas personalidades. Esse tipo de material constitui, portanto, uma importante via de acesso ao imaginário sexual humano.

\section{Referências}

Ahmed, S. M. S. (1981). Graffiti of Canadian high school students. Psychological Reports, 49, 559-562.

Anderson, S. J., \& Verplanck, W. S. (1983). When walls speak, what do they say? The Psychological Record, 33, 341-359.

Arluke, A., Kutakoff, L., \& Levin, J. (1987). Are the times changing? An analysis of gender differences in sexual graffiti. Sex Roles, 16, 1-7.

Björkqvist, K. (1994). Sex differences in physical, verbal, and indirect aggression: A review of recent research. Sex Roles, 30, 177-188.

Bruner, E., \& Kelso, J. P. (1980). The voices and words of women and men. New York: PergamoBjökqvn Press. 
Burbank, V. K. (1994). Cross-cultural perspectives on aggression in womem and girls: An introduction. Sex Roles, 30, 169-176.

Burbank, V. K. (1987). Female aggression in cross-cultural perspective. Behavior Science Research, 21, 70-100.

Clark, R. D., \& Hattfield, E. (1989). Gender differences in receptivity to sexual offers. Journal of Psychology and Human Sexuality, 2, 3955.

Cole, C. M. (1991). "Oh wise women of the stalls ..." Discourse \& Society, 2, 401-411.

Coyne, J. C., Sherman, R. C., \& O'Brien, K. (1978). Expletives and women's place. Sex Roles, 4, 827-835.

Ehrlichman, H., \& Eichenstein, R. (1992). Private wishes: Gender similarities and differences. Sex Roles, 26(9/10), 399-422.

Eibl-Eibesfeld, I. (1989). Human Ethology. New York: Aldine de Gruyter.

Herek, G. M. (1989). Hate crimes against lesbians and gay men: Issues for policy and research. American Psychologist, 44, 948-955.

Holmes, J. (1992). Women's talk in public contexts. Discourse \& Society, 3, 131-150.

Innala, S. M., \& Ernulf, K. E. (1992). Understanding male homosexual attraction: An analysis of restroom graffiti. Journal of Social Behavior and Personality, 7, 503-510.

Kerns, J. G.; \& Fine, M. A. (1994). The relation between gender and negative attitudes toward gay men and lesbians: Do gender role attitudes mediate this relation? Sex Roles, 5/6, 297-307.

Kinsey, A. C., Pomeroy, W. B., Matin, C. E., \& Gebhardt, P. H. (1953). Sexual behavior in the human female. Philadelphia, PA: Saunders.

Kutakoff, L. (1972). Sex differences in bathroom graffiti. Dissertação de Mestrado não-publicada, Boston University.

Levin, J., \& Arluke, A. (1985). An exploratory analysis of sex differences in gossip. Sex Roles, 12, 281-193.

Loewenstine, H. V., Ponticos, G. D., \& Paludi, M. A. (1982). Sex differences in graffiti as a comunication style. Journal of Social Psychology, 117, 307-308.

Lomas, H. D. (1980). Graffiti: Additional clinical observations. The Psychoanalytic Review, 67(1), 139-142.

Mason, K. O., Czajka, J. L., \& Arber, S. (1976). Change in U.S. women's sex-role attitudes, 1964-1974. American Sociological Review, 41, 573-596.

Michael, R.T., Gagnon, J.H., Laumann, E.O., \& Kolata, G. (1975). Sex in America. New York: Warner Books.

Mendel, A. O. (1974). Personality in handwriting: A handbook of American graphology. New York: Ungar Publishing. 
Neto, R. B. (1992). Banheiros de Pompéia. Folha de São Paulo, São Paulo, 20 de setembro.

Norusis, M. J. (1993). SPSS for Windows: Advanced statistics, release 6.0. Chicago: SPSS.

Nwoye, O. G. (1993). Social issues on walls: graffiti in university lavatories. Discourse \& Society, 4, 419-442.

Olowu, A. A. (1983). Graffiti here and there. Psychological Reports, $52,986$.

Otta, E. (1993). Graffiti in the 1990s: a study of inscriptions on restroom walls. Journal of Social Psychology, 133, 589-590.

Otta, E., Lafraia, L. M., Hoshino, R. L., Teixeira, R. P., Vallochi, S. L., \& Santana, P. R. (1996). Musa latrinalis: gender differences in restroom graffiti. Psychological Reports, 78, 871-880.

Peretti, P. O., Carte, R., \& McClinton, B. (1977). Graffiti and adolescent personality. Adolescence, 45, 31-42.

Sechrest, L., \& Flores, L. (1969). Homosexuality in the Philippines and the United States: The handwriting on the wall. Journal of Social Psychology, 79, 3-12.

Secherest, L., \& Olson, A. K. (1971). Graffiti in four types of institutions of higher education. Journal of Sex Research, 7, 62-71.

Silva, A. A. (1996). Sexo Casual. Viver Psicologia, julho, 16-18.

Singer, E. (1974). Personality in Handwriting. New York: Hippocrene Books.

Sprecher, S., \& Sedikides, C. (1993). Gender differences in perceptions of emotionality: The case of close heterosexual relationships. Sex Roles, 28, 511-530.

Thorton, A., \& Freedman, D. (1979). Changes in the sex role attitudes of women, 1962-1977: evidence from a panel study. American Sociological Review, 44, 831-842.

Wales, E., \& Brewer, B. (1976). Graffiti in the 1970's.Journal of Social Psychology, 99, 115-123.

White, M. J. (1977). Counternormative behavior as influenced by deindivituating conditions and reference group salience. The Journal of Social Psychology, 103, 75-90. 
250 R. P. Teixeira e E. Otta

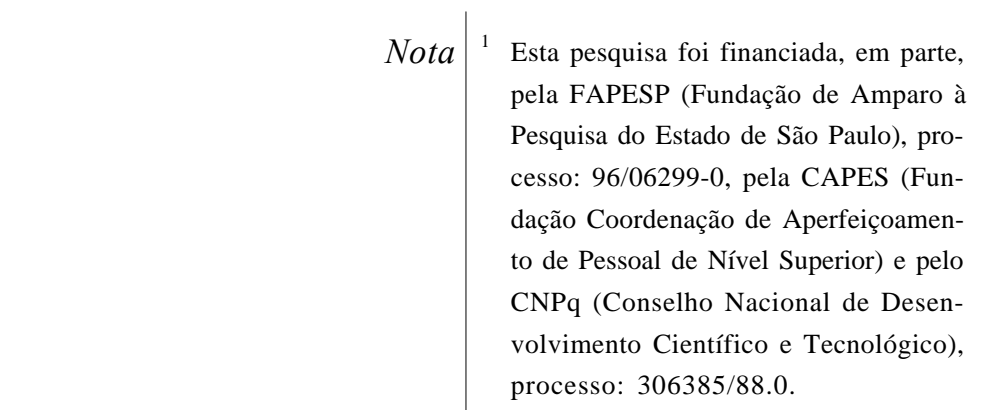

Renata Plaza Teixeira é

Sobre as autoras mestranda do Departamento de Psicologia Experimental do Instituto de Psicologia da Universidade de São Paulo (IPUSP) e bolsista da CAPES; Emma Otta é professora do Departamento de Psicologia Experimental do IPUSP e bolsista do CNPq. Endereço para correspondência: Av. Prof. Mello Moraes, 1721, Cidade Universitária, Butantã, São Paulo, SP. CEP 05508-900. Telefone: (011) 8184448. Fax: (011) 818-4357. Emails: renatapt@usp.br e emmaotta@usp.br. 